\title{
0 simbolismo da depressão na perspectiva junguiana
}

\author{
The symbolism of depression in the junguian perspective
}

Francisco Purcotes Júnior

Graduado em Psicologia pela Faculdade Evangélica do Paraná (Fepar), pós-graduando em Psicologia Analítica e Religião Oriental e Ocidental (ICHTHYSFAVI), Curitiba, PR - Brasil, e-mail: purcotes@hotmail.com

Recebido: $15 / 12 / 2010$ Received: 12/15/2010

Aprovado: 24/03/2011 Approved: 03/24/2011

\section{Resumo}

Cada vez mais, pessoas aparecem nos consultórios médicos e psicológicos com sintomas de depressão. Dentre eles, podem ser citados a tristeza, vontade de não fazer nada, apatia, desinteresse, insônia, sensação de vazio, entre outros. Assim, é deveras importante que entre os profissionais haja o esclarecimento e a discussão sobre formas de tratamento, além de, se possível, que haja novos pontos de vista sobre esse tópico. Este texto tem a finalidade de apresentar, explicar e descrever como se realiza o trabalho com pacientes depressivos segundo a proposta teórica do psiquiatra suíço Carl Gustav Jung, criador da Psicologia Analítica, e como esta abordagem trabalha os conteúdos e sintomas depressivos. Para isso, o texto propõe uma básica explanação sobre a depressão e como a doença é vista no âmbito médico e psicológico na atualidade, além de relatar as imagens e símbolos que surgem durante a vivência dos sintomas pelos pacientes que sofrem. Tudo isso será relatado por meio de uma revisão na literatura já existente.

Palavras-chave: Depressão. Pacientes. Psicologia Analítica.

\begin{abstract}
Increasingly, people appear in medical and psychological offices with symptoms of depression, including, sadness, will of doing nothing, indifference, apathy, insomnia, feeling of emptiness, among others. So it is very important that among the professionals, there has to be a clarification and discussion of treatment options, and if possible, the development of new points of view about this topic. This text aims to present, explain and describe how is the work with depressed patients according to the theoretical proposal of Swiss psychiatrist Carl Gustav Jung, the creator of Analytical Psychology and how this approach works the content and depressive symptoms. For this, the text offers a basic explanation of depression and how this disease is seen in the medical and psychological fields today, in addition to reporting the images and symbols that arise during the experience of symptoms by patients who suffer. All this will be reported through a review of existing literature.
\end{abstract}

Keywords: Depression. Patients. Analytical Psychology. 


\section{Introduç̃̃o}

0 território da depressão é uma região bem triste. Nele sempre se sofre, às vezes morre-se. Quem o visita, jamais o esquece e clama que se deve, se possível, evitá-lo, ou, se já se entrou nele, sair o mais depressa possível. Para sair, em primeiro lugar é preciso saber o que nem sempre é evidente - que se está nele (Cuche \& Gérard, 1994, p. 143).

Humor deprimido na maior parte do dia, sentir-se triste ou vazio, diminuição do interesse e do prazer, insônia, fadiga e perda de energia são alguns dos critérios médicos para indicação de um episódio depressivo. Vários episódios configuram um transtorno depressivo.

Com o passar do tempo, médicos psiquiatras e psicólogos têm recebido em seus consultórios um número cada vez maior de pacientes com esses sintomas, o que torna essencial hoje em dia que os profissionais que lidam com a mente humana estejam preparados para lidar com o depressivo e disponham de alternativas que os permitam compreender o que realmente se passa com a alma do paciente.

As visões médica e psicológica sobre a depressão diferem em alguns pontos. 0 diagnóstico e o tratamento baseado em medicamentos parecem ser o foco dos psiquiatras, enquanto a busca da alma e o sentido do sofrimento do paciente é o que procura um psicólogo de orientação analítica.

Assim, este trabalho buscará explicar e compreender a depressão em suas visões médicas e psicológicas e apresentará, como forma de tratamento com o depressivo, a proposta de Carl Gustav Jung e da Psicologia Analítica.

Tirar a tristeza do paciente, animá-lo, propor atividades que o distraiam e medicá-lo, parecem ser os tratamentos mais normais e efetivos contra a depressão. Entretanto esses métodos acabam sendo apenas paliativos, visto que os sintomas são apenas reprimidos, e o verdadeiro sofrimento torna-se inconsciente. Como a Psicologia Analítica explica, os conteúdos inconscientes não desaparecem, mas em algum momento irão se manifestar, assim, viver e encarar a tristeza se tornam outra alternativa, mais trabalhosa, escura e perigosa, porém um caminho cujo fim é mais claro, feliz e duradouro.

\section{Desenvolvimento}

De acordo com o Manual Diagnóstico e Estatístico de Transtornos Mentais (American Psychiatric Association, [APA], 2002, p. 345), o Transtorno
Depressivo Maior é caracterizado por um ou mais Episódios Depressivos Maiores, ou seja, o paciente no mínimo deve apresentar duas semanas de humor deprimido ou perda de interesse, acompanhado de mais quatro sintomas de depressão.

Nove sintomas para Episódio Depressivo Maior são descritos no manual como base para a formulação do diagnóstico (APA, 2002, p. 354):

Acentuada diminuição do interesse ou prazer em todas ou quase todas as atividades na maior parte do dia, quase todos os dias (indicado por relato subjetivo ou observação feita por terceiros) ... Humor deprimido na maior parte do dia, quase todos os dias, indicado por relato subjetivo (p. ex., sente-se triste ou vazio) ou observação feita por terceiros (p. ex., chora muito).

Os critérios seguem:

Perda ou ganho significativo de peso sem estar em dieta, ou diminuição ou aumento do apetite quase todos os dias.

Insônia ou hipersonia quase todos os dias.

Agitação ou retardo psicomotor quase todos os dias.

Fadiga ou perda de energia quase todos os dias.

Sentimento de inutilidade ou culpa excessiva ou inadequada, quase todos os dias.

Capacidade diminuída de pensar ou concentrar-se, ou indecisão, quase todos os dias.

Pensamentos de morte recorrentes, ideação suicida recorrente sem um plano específico, tentativa de suicídio ou plano específico para cometer suicídio (APA, 2002, p. 355).

Segundo Cuche e Gérard (1994), as pessoas têm entre $5 \%$ a $10 \%$ de risco de ter depressão durante a vida, entretanto esses números não são absolutos, visto que grande parte das pessoas que sofrem nunca vão ao médico, logo não são registradas.

Graças às rápidas transformações que ocorrem na sociedade, o crescimento do número de deprimidos é proporcional à esperança de vida. Estresse psicossociais e as adaptações necessárias para a sobrevivência são alguns dos fatores que justificam esse aumento (Cuche \& Gérard, 1994, p. 12).

Ainda para os autores Cuche e Gérard (1994, p. 12), a vida moderna impõe diversas mudanças, costumes, modos de vida, e a impossibilidade de o indivíduo se adaptar a essas situações ocasiona a depressão.

Dalgalarrondo (2008) afirma que com frequência as reações e síndromes depressivas aparecem após perdas significativas, podendo ser de algum 
ente querido, um emprego, moradia, status ou de algo puramente simbólico.

Jung (2008) afirma que o aumento considerável populacional, sobretudo nas cidades grandes, exerce sobre nós um efeito depressivo.

O diagnóstico de Transtorno Depressivo Recorrente é dado quando, no decorrer da vida, o indivíduo apresentou mais de um Episódio Depressivo, não podendo ser intercalado com episódios maníacos ou hipomaníaco (Dalgalarrondo, 2008, p. 311).

Segundo a classificação médica, Dalgalarrondo pontua alguns subtipos de síndromes e transtornos depressivos: Episódio ou fase depressiva e Transtorno Depressivo Recorrente, Distimia, Depressão atípica, Depressão tipo melancólica ou endógena, Depressão psicótica, Estupor depressivo, Depressão agitada ou ansiosa e Depressão secundária ou orgânica.

Pesquisas demonstram que $80 \%$ dos pacientes com sintomas depressivos não recebem o tratamento adequado (Cuche \& Gérard, 1994, p. 16).

Entre jovens e idosos, a depressão é uma doença muitas vezes mortal, e hoje é tão frequente que, segundo as pesquisas, uma pessoa entre cinco, ficou, fica ou ficará deprimida (Cuche \& Gérard, 1994, p. 17).

Segundo Styron (1991) uma depressão realmente grave não desaparece do dia para a noite, e a maioria das pessoas sente-se pior pela manhã e vão melhorando com o decorrer do dia.

Para Styron, (1991, p. 63-64) a dor depressiva é como um afogamento ou sufocação. É como se o seu raciocínio estivesse sendo inundado por uma onda venenosa e invencível que impedia qualquer reação ao mundo exterior. "Uma sensação de perda que está ligada a uma certeza de que a vida foge a grande velocidade". "Toda ideia de futuro desaparece".

O primeiro passo para o tratamento, segundo esse modelo médico, "consiste em ajudar de maneira ativa o paciente a gerir sua vida, seu tratamento e o conjunto de sua situação". Esse método inclui "não hesitar em dar conselhos e orientações e a ajuda de medicamentos" (Cuche \& Gérard, 1994, p. 162).

De acordo com o modelo médico psiquiátrico de tratamento para os pacientes depressivos, a psicoterapia é aconselhada apenas num segundo momento de tratamento, visto que Cuche e Gérard (1994) justificam que a psicoterapia, no seu sentido clássico, exige uma capacidade de pensar, de dispor livremente de raciocínio, de inteligência e de associação de ideias, o que, segundo os autores, são coisas difíceis para o deprimido. Os autores definem a cura da depressão como o "retorno ao estado anterior".

Diferentemente do modelo médico, o diagnóstico não é o essencial para o trabalho com a depressão para a Psicologia Analítica. Segundo Jung (2006, p. 158), "Naturalmente, é necessário que um médico tenha o conhecimento dos assim chamados métodos. Mas deve evitar o engajamento fixo de um caminho determinado, rotineiro". Carl Gustav Jung nasceu em 26 de julho de 1875 em Kesswil, na Suíça, seu pai (Johann Paul Achilles Jung) era pastor protestante e sua mãe (Emilie Jung) era filha de um pastor Grinberg (2003, p. 12).

Segundo Grinberg (2003, p. 13), o primeiro sonho que Jung se recorda ocorreu quando ele tinha mais ou menos três anos. Alguns anos mais tarde, Jung afirmou que esse primeiro sonho ocorrera "para que a mais intensa luz possível se produzisse na escuridão".

Jung cresceu e se tornou psiquiatra, percebeu que os pacientes possuem segredos, histórias que não são contadas e que são fundamentais para que o profissional possa ajudar.

Para mim, a verdadeira terapia só começa depois de examinada a história pessoal. Essa representa o segredo do paciente, segredo que o desesperou. Ao mesmo tempo, encerra a chave do tratamento. É, pois, indispensável que o médico saiba descobri-la. Ele deve propor perguntas que digam respeito ao homem em sua totalidade e não limitar-se apenas aos sintomas. Na maioria dos casos, não é suficiente explorar o material consciente. Conforme o caso, a experiência de associações pode abrir o caminho à interpretação dos sonhos (Jung, 2006, p. 144).

De acordo com Jung (2006), apenas a formação psiquiátrica não é suficiente, pois não é possível tratar uma psicose, por exemplo, sem compreender a simbologia. Ele teve então que estudar Mitologia. Afirma Jung: "Uma simples formação médica não é suficiente, porquanto o horizonte da alma humana vai muito além do gabinete de consulta".

Para Jung (2008), as pessoas sofrem cada vez mais uma sensação de terrível vazio e tédio, esperando por algo que nunca acontece. Elas tentam se distrair com cinema, televisão, espetáculos esportivos e política, mas, cansadas, sempre voltam ao deserto de suas vidas.

Em sua vida pessoal, defrontar-se com a depressão foi uma difícil tarefa que perdurou durante anos. Segundo Grinberg (2003, p. 40), a decisão de Jung em enfrentar o inconsciente foi no dia 12 de dezembro de 1913. 
Sentado em meu escritório, considerei mais uma vez os temores que sentia, depois me abandonei à queda. 0 solo pareceu ceder aos meus pés e fui como que precipitado numa profundidade escura. Não pude evitar um sentimento de pânico. Mas de repente, sem que tivesse atingido uma grande profundidade, encontrei-me - com grande alívio - de pé, numa massa mole e viscosa. A escuridão era quase total; pouco a pouco meus olhos se habituaram a ela, que parecia um crepúsculo sombrio. Diante de mim estava a entrada de uma caverna obscura (Jung, 2006, p. 206).

De acordo com Jung, (1986, p. 370), o homem precisa conhecer toda essa horrível dúvida, todo o desespero e confusão da alma, pois ele só está ligado às imagens que ele mesmo cria, e não a algo externo como partidos e credos. "Toda convicção da minha vida agora repousa na crença de que a solidão, longe de ser um fenômeno raro e curioso, é o fato central e inevitável da existência humana".

Moustakis (citado por Lyra, 2001, p. 138) afirma que "A solidão é uma condição da vida humana, uma experiência do ser humano que possibilita ao indivíduo sustentar, estender e aprofundar sua qualidade humana ..." Todas as tentativas de fugir dessa experiência existencial da solidão resultam em autoalienação. Quando o homem foge de uma verdade fundamental da vida e nega essa solidão, ele se fecha para um importante passo rumo ao seu crescimento pessoal.

Lyra (2001, p. 134) diz que "quando seguimos as pegadas dos caminhos que nos conduzem à completude, saberemos que este caminho sempre desembocará na Fonte Espiritual, que é um lugar de solidão".

Mazzocchi, Forzani e Tallarico (1995, p. 27-30) explicam: "Nascemos sós, morremos sós, caminhamos sós: sós no sentido de que ninguém pode fazê-lo por nós. A nossa unicidade é o nosso deserto e, ao mesmo tempo, o sinal da unidade de cada ser". Assim, retirar o paciente da experiência de solidão, equivale a retirá-lo de sua busca pessoal, de uma experiência única. De acordo com Cuche e Gérard (1994), quando dizemos a um deprimido para se animar, é como se estivéssemos dizendo a um homem sem pernas correr mais, o que agravará seu sentimento de culpa.

A definição simbólica dos comportamentos depressivos, segundo Mazzocchi, Forzani e Tallarico (1995, p. 27-30), em nossas vidas também experimentamos esse "deserto", seja ele por um sofrimento físico ou interior, nessa hora ninguém pode confortar-nos. Todas as coisas que dávamos importância, inclusive os afetos, passam para um segundo plano, assim descobrimos a solidão. Nesse deserto, somos conduzidos novamente a nossa essência, à raiz, e corremos o grande risco de ter vivido em vão, se ignorarmos essa fonte. Podemos ter companheiros de viagem, mas nenhum pode caminhar por nós, ou no nosso lugar.

Lyra (2001, p. 137) apresenta a ideia que todo movimento de aumento de clareza e consciência começa com uma traumática separação. No caso da depressão, essa separação do mundo e busca pelo seu próprio caminho serve, ao fim, para o encontro da luz, eis o porquê desse momento não poder ser ignorado, mas vivido. Lyra (2001, p. 124) comenta que "tudo aquilo que representa algum perigo para nós, é, da mesma forma, o único caminho que conduz à salvação".

Os símbolos e imagens que aparecem num estado depressivo são efetivamente importantes para o processo terapêutico, visto que é por meio deles que o paciente encontrará as suas formas de lidar com a depressão. Não há um padrão de imagens e símbolos para cada transtorno ou doença, cada pessoa manifestará seus sintomas de uma forma diferente, fato que torna a psicoterapia necessária nesse tratamento, já que o modelo médico não focará a parte simbólica da psique, como a Psicologia Analítica propõe.

Outra imagem recorrente que os pacientes depressivos trazem para a terapia simbolizando seu estado psíquico e como se sentem é a queda ou a descida. Essa imagem é antiga e vem da mitologia grega.

Os gregos denominavam uma queda como catábase. Essa decida representa um "ir sem saber para onde", sem rumo, é o retomar o contato com suas raízes, e geralmente leva o indivíduo ao isolamento, pois separa a pessoa daqueles com quem caminhava, ele vai para o "porão", para um lugar mais baixo, inferior (Lyra, 2001, p. 163).

Aprender a suportar o insuportável, eis a tarefa que nos é exigida se queremos tratar a ferida originária da dor da separação e do abandono, em que experienciamos a máxima solidão. Não é possível evitar a solidão, pois a sentimos mesmo quando rodeados de pessoas. Só podemos vencê-la indo ao seu encontro, aprendendo a suportá-la, ainda que comecemos com pequenas doses. 0 veneno em pequenas doses é o antídoto do próprio veneno (Lyra, 2001, p. 161). 
Segundo Hollis, (1999, p. 121-122) "O tormento do inferno é a única maneira de atravessar a abertura que Dante divisou depois de sua temível jornada. Somente a descida ao Hades é capaz de nos libertar do Hades".

Hades é um deus antigo, ele é o soberano do submundo, seu reino também é conhecido como Hades (Johnson \& Ruhl, 2010, p. 64).

Hades e o submundo não são apenas símbolos de perda e da morte, mas também de riqueza. Segundo Johnson e Ruhl (2010, p. 65),

O senhor do submundo é uma figura criativamente transformadora, o correspondente masculino de Demeter, a deusa da fertilidade que gera os grãos e frutos da terra. De fato, a imersão nesse reino propicia uma fecundidade interna. Falando de maneira psicológica, precisamos ir ao submundo para recuperar as riquezas.

Johnson e Ruhl (2010, p. 77) reforçam que "Hades não é apenas a morada da perda, dos lamentos e da depressão; é um reino transformativo, pleno de riquezas, que promete uma nova colheita de potencial de vida".

A mitologia também retrata esse tema quando fala sobre a jornada do herói: a descida ao inconsciente é uma das etapas necessárias para o seu desenvolvimento. Segundo Campbell (2008, p. 138), a aventura do herói é sempre perigosa, pois se distancia da esfera conhecida da consciência rumo ao grande desconhecido. É a travessia do mundo consciente para o inconsciente e é representado por muitas imagens. Pode-se mergulhar no oceano, entrar no deserto, perder-se numa floresta escura ou uma cidade estranha. Pode ser uma ascensão ou uma descida... é o caminho rumo ao desconhecido, por um portão, por uma caverna ou por rochas que se chocam. Vários heróis da mitologia, como Ulisses, Orfeu e Hércules desceram ao Hades para completar sua aventura.

A literatura também traz imagens que relatam o sentimento que o depressivo passa durante essa fase. Na obra "Memórias do subssolo", o autor diz: "Quanto mais o bem e todas as coisas "belas e sublimes' se tornavam claras à minha consciência, mais profundamente eu me afundava na minha lama, mais eu me sentia capaz de me enterrar definitivamente" (Dostoievski, 2004, p. 70).

Um dos temas exaustivamente estudados por Jung para desenvolver sua psicologia foi a alquimia, que também retrata o processo depressivo e as etapas de transformação psíquicas que ocorrem durante o desenvolvimento de sua personalidade. A alquimia descreve as etapas de transformação dos elementos químicos. Jung demonstra como esses mesmos processos podem ser aplicados para os elementos psicológicos e como ocorrem essas transformações de energia psíquica.

Segundo Jung (1991, p. 244, § 334), a Nigredo é a primeira fase, é a fase do caos, da confusão e da escuridão, é a morte do produto químico, de forma que possa haver a transformação. 0 metal que representa essa fase é o chumbo. A partir dessa morte psicológica, ocorre a segunda fase, a Albedo; é a aurora, a lavagem, o batismo, o embranquecimento, a alma morreu e foi liberta, o preto se transforma em branco, ressuscitou, segundo alguns alquimistas é a meta do processo, é a fase Lunar; o metal que simboliza é a prata. Mas o nascer do sol não é essa fase, o branco se transforma em brilho, é a elevação do fogo à sua maior intensidade. Essa fase se chama Rubedo, e, quando o indivíduo volta a brilhar, ele já passou pelo escuro, pela morte, ressuscitou, ficou claro, enxergou a luz e, no fim, se tornou a luz, sua energia foi transformada.

Associando a Alquimia com a Psicologia, podemos entender as fases da depressão sentidas pelo paciente. A Nigredo, fase escura, em que não há saídas e não existe luz, o paciente se sente realmente no fundo do poço e pensa em morrer. 0 ser não suporta mais a dor, mas não foge dela, e, enfim, ocorre a morte psicológica do Sujeito que sofre. Como na Alquimia, as transformações dos metais ocorriam da mesma forma que as transformações psíquicas, e como o sujeito suportou a dor e não correu dela, agora pode nascer um novo ser, já livre da dor, que foi integrada.

A segunda fase alquímica, a Albedo, representa esse renascimento; o peso e a dor não mais existem, e o que pode definir o novo ser é o alívio.

Na terceira fase, a Rubedo, existe um novo ser que agora precisa viver. Ele parte rumo à vida, volta a sorrir e agora pode desfrutar da felicidade e alegria que o Sujeito que sofre nunca imaginou voltar a sentir.

De acordo com Lyra (2001, p. 164), a depressão é parte de uma angústia e representa uma descida, uma puxada para baixo, para onde não queremos ir, entretanto é uma dor necessária, só então, algo novo pode surgir em nós, e, quando entendemos isso, podemos até pedir para "afundar".

Segundo Jung (2008), para que a pessoa possa perceber esses fatos, é quase sempre necessária que haja uma crise em sua vida. 
0 propósito terapêutico em auxiliar o paciente com depressão, diferentemente do propósito médico psiquiátrico, está em, como diz Jung (2008, p. 221), "Voltar-se para as trevas que se aproximam, sem nenhum preconceito e com toda a simplicidade, e tentar descobrir qual o seu objetivo secreto e o que vem solicitar do indivíduo".

Jung (2008, p. 221) explica esse processo:

O propósito secreto dessas trevas que se avizinham geralmente é tão invulgar, tão especial e inesperado que, via de regra, só se consegue percebê-lo por meio dos sonhos e fantasias que brotam do inconsciente. Se focalizarmos nossa atenção sobre o inconsciente sem suposições precipitadas ou rejeições emocionais, o propósito há de surgir um fluxo de imagens simbólicas de grande proveito. Mas nem sempre isso acontece. Algumas vezes aparece, inicialmente, uma série de dolorosas constatações do que existe de errado em nós e em nossas atitudes conscientes. Temos então que dar início a esse processo engolindo todo tipo de verdades amargas.

De acordo com Chopra (2009, p. 82), "é na escuridão que inicia a jornada da alma, é lá que a verdade está disfarçada ou incompreendida".

O homem tenta evitar o sentido da depressão que sente, e o faz por meio de inúmeros artifícios ou ilusões: planos de sucesso exterior, drogas e bebidas, troca de mulheres, etc. Assim ele pensa manter suas energias quando, na verdade, está amontoando pecado psicológico em cima de pecado psicológico. 0 ideal seria que o homem aceitasse suas más e obscuras disposições, encarando-as como um convite para encontrar sua alma e ser uma pessoa plena (Sanford, 1987, p. 79).

Segundo Styron (1991, p. 91), "Se a depressão não tivesse um fim, então o suicídio seria o único remédio". Mas a depressão não pode ser considerada como o aniquilamento da alma, ela pode ser dominada.

Para Styron (1991) o tempo da depressão não muda, e sua luz é sempre marrom-escura.

0 alívio da dor, proposto pelo modelo psiquiátrico de tratamento da depressão não existe segundo Styron (1991, p. 67):

Na depressão, essa fé no alívio da dor, na recuperação final, não existe. A dor é implacável e essa condição torna-se intolerável por sabermos de antemão que não vai aparecer nenhum remédio - no período de um dia, numa hora, num mês ou num minuto. Sabemos que qualquer pequeno alívio é temporário, que será seguido por mais dor. A desesperança, mais do que a dor, destrói a alma.
0 terapeuta, como um parceiro de viagem para o paciente, ajuda o mesmo a enfrentar essa tempestade. Diz Styron (1991, p. 80), "Se sobrevivem à tempestade propriamente dita, sua fúria quase sempre diminui e por fim desaparece. Misteriosa na chegada, misteriosa na partida, a doença segue seu curso, e finalmente encontramos a paz".

Jung (2011, p. 18) confirma como o terapeuta pode agir com o paciente:

Como se sabe, o terapeuta se relaciona com outro sistema psíquico, não só para perguntar, mas também para responder; não mais como superior, perito, juiz e conselheiro, mas como alguém que vivencia junto, que, no processo dialético, se encontra em pé de igualdade com aquele que ainda é considerado o paciente.

Segundo Styron (1991), mesmo nos casos mais graves de depressão, as vítimas sobrevivem e vivem tão felizes quanto as que nunca tiveram depressão.

Dahlke (2009) conta como foi a vida do escritor Herman Hesse e como este seguiu o seu processo de individuação que Jung descreveu e recomendou. Assim, ficou clara a possibilidade de encontrar um caminho no deserto da depressão. A busca de si mesmo, o encontro com o inconsciente e com as imagens da depressão são essenciais para o desenvolvimento pessoal.

Para Grinberg (2003, p. 136), "os arquétipos são conteúdos vazios e não preenchidos, são formas coletivas e universais, padrões de experiência que expressam a capacidade criativa da psique".

0 arquétipo de Saturno ou Cronos (Deus do tempo), segundo a mitologia grega, é o que tem relação com os temas de despedida, da morte e da depressão. Saturno é um planeta frio, distante, seco, quem está sobre influência desse arquétipo sente essa solidão (Dahlke, 2009, p. 131).

Não é por acaso, diz Dahlke (2009, p. 65), que o vazio e a falta do sentido são sintomas de depressão. Recusar-se a seguir um chamado é o mesmo que negar o sentido da vida.

O símbolo da água também é visto como relacionado à depressão, entretanto essa não é a água clara de um lago, mas sim a água parada de um pântano (Dahlke, 2009, p. 211).

Dahlke cita uma frase dita pelo Xeique Saadi, da cidade de Chiraz (1184-1291): "Tesouros inimagináveis estão enterrados no fundo do mar. Mas, se preferes segurança, é melhor que fiques na margem". 
De acordo com Da Silva (2011), todos nós temos nossos momentos depressivos. Ele cita a frase de Jung para demonstrar como pode ser realizado um trabalho psicológico com a depressão.

Grun (citado por Da Silva, 2011) afirma:

[...] as depressões são um estímulo para se percorrer novos caminhos, seguir o caminho interior. Entretanto, muitas pessoas recusam-se a dar esse passo a frente. Elas ficam presas ao seu passado e procuram dar prosseguimento aos padrões de vida da primeira metade da vida.

0 psicólogo Frederic Flach diz que: "a depressão é sempre uma chance de vida, ela nos presta um serviço, pois nos induz de forma natural à recuperação do tempo e reflexão sobre o nosso objetivo da vida" (Da Silva, 2011).

Em entrevista para a revista Istoé, Chalub (2010) afirma que hoje em dia tanto pacientes quanto médicos confundem tristeza com depressão. 0 autor afirma. "Não se pode mais ficar triste, entediado, porque isso é imediatamente transformado em depressão".

Chalub (2010), sobre a conduta médica adotada quando em contato com pacientes depressivos, afirma: "É a medicalização de uma condição humana, a tristeza. É transformar um sentimento normal, que todos nós devemos ter, dependendo das situações, numa entidade patológica".

A procura dos pacientes por médicos psiquiatras para tratar a depressão, sem a participação do psicólogo e da psicoterapia, psicologicamente falando, os leva a um caminho mecânico e altamente não terapêutico, já que de, acordo com os métodos médicos apresentados, apenas reprimirá os conteúdos "tristes" e sombrios, deixando o paciente mais vulnerável e à mercê do inconsciente, o que pode ser perigoso.

Segundo Jung (2011, p. 28), quando fala sobre o papel do médico:

Os conhecimentos que se exigem do médico não constaram do seu currículo na faculdade. Não foi preparado para cuidar da alma humana, pois ela não é problema psiquiátrico ou fisiológico, e muito menos biológico. É um problema psicológico. A alma é um território em si, com leis que lhe são próprias. A essência da alma não pode ser derivada de princípios de outros campos da ciência, caso contrário violar-se-ia a natureza particular do psiquismo.

Se não ficarmos tristes em algumas situações, isto sim, é um problema (quando perdemos um ente querido, por exemplo). Segundo Chalub (2010), o homem não aceita mais sentir coisas humanas, como a tristeza. Ficar triste, em geral, não justifica o uso de medicamentos. Para o entrevistado, os médicos atualmente precisam suprir a demanda. Assim, em geral, um paciente que diga em uma consulta que está triste, se for aconselhado uma psicoterapia, não sairá satisfeito e procurará outro médico; este receitará um antidepressivo, o que fará o paciente se sentir melhor, e voltar outras vezes.

As raízes da depressão estão na infância. Os acontecimentos atuais não levam à depressão verdadeira, só muito raramente. Justamente o contrário do que se imagina. Mas mexer na infância é muito doloroso. Não tem remédio para isso. Precisa de terapia, de análise, mas as pessoas não querem fazer, não querem mexer nas feridas. Então é melhor colocar um esparadrapo, para não ficar doendo, e pronto. É a solução mais fácil (Chalub, 2010).

O desamparo é uma condição humana, e é o que ocorre hoje em dia, as pessoas estão cada vez mais desamparadas, mas precisamos enfrentar esse desamparo, assim como o fracasso, o isolamento e a solidão Chalub (2010).

Assim, a felicidade não se baseia apenas em coisas positivas, mas também compreende aceitar as limitações, o sofrimento, as incompetências e fracassos. "É também ficar triste de vez em quando" (Chalub, 2010).

\section{Considerações finais}

De acordo com o trabalho apresentado e com a revisão na literatura existente, fica evidente a necessidade de, hoje em dia, os profissionais que trabalham com a mente humana, se atualizarem a respeito de métodos e propostas para o trabalho com a depressão.

É evidente como cada dia mais pessoas vão aos consultórios médicos e psicológicos com tristeza, tédio ou vazio, sintomas do que se chama de depressão.

Demonstra-se como há diversas formas de trabalho com os pacientes depressivos, e como são diferentes as propostas médico-psiquiátricas e a psicológica de orientação analítica.

Na proposta médica, há a inclusão de medicamentos, e são evidenciados os critérios diagnósticos segundo o Manual de Transtornos Mentais (DSM IV), e 
por meio de um diagnóstico é definido um plano de tratamento, busca-se o alívio da dor e do sofrimento.

Na proposta psicológica, pela abordagem Analítica, o alívio da dor e do sofrimento vem com o enfrentamento dessas situações. Não se busca "fugir", ou retirar uma dor, pelo contrário, a pessoa, por meio do processo de psicoterapia, vai ganhando forças para entrar em sua depressão, para enfrentar seus medos, dores e sofrimentos.

Esse processo faz parte do que Jung chama Processo de Individuação: o indivíduo entra em contato com ele mesmo, muitas vezes com seu pior lado, com aquilo que odeia, que não suporta, que não é aceito socialmente. Para Jung, deixar de lado esses conteúdos obscuros pode piorar o estado da pessoa. Ela reprime ou "anestesia" esses conteúdos, entretanto, eles não deixarão de existir, mas voltarão ao sujeito em forma de sintoma, sonhos, fantasias. Assim, se dá a importância de não ignorar-se as fantasias, os sonhos e as imagens que aparecem à pessoa quando esta passa por uma fase negra, por uma depressão.

A psicoterapia é indicada apenas num segundo momento ao sujeito diagnosticado depressivo. A prioridade do médico é trabalhar os sintomas e aliviar a dor. Entretanto, fica claro como afastar o sujeito de SUA dor é algo tão destrutivo quanto retirar o sofrimento dele. Ao contrário da opinião médica sobre a psicoterapia, o psicólogo precisa saber o momento em que o paciente precisa de medicamentos e de auxílio psiquiátrico, já que há inúmeros casos em que isso se torna necessário. Caso haja necessidade, não há problema em encaminhar o paciente para um trabalho com o médico paralelamente.

Quando o médico retira a dor, a ansiedade e o sofrimento do paciente, ele está tirando também algo que pertence ao paciente, que faz parte de sua história e que, com certeza, faz parte do seu processo de desenvolvimento, de individuação. "Somente a descida ao Hades é capaz de nos libertar do Hades".

\section{Referências}

American Psychiatric Association, (APA), 2002. Manual Didático e Estatístico de Transtornos Mentais. (4⿳亠口了. ed.). Porto Alegre, RS: Artmed.

Campbell, J. (2008). Mito e transformação. São Paulo: Ágora.
Chalub, M. (2010). 0 homem não aceita mais ficar triste. Revista Istoé, Ed. 2115. Recuperado em 17 set. 2011, em http://www.istoe.com.br/assuntos/entrevista/detalhe/74405_0+HOMEM+NAO+ACEITA+MAIS+FICAR + TRISTE

Chopra, D. (2009). 0 terceiro Jesus: 0 Cristo que não podemos ignorar. Rio de Janeiro: Rocco.

Cuche, H., \& Gérard, A. (1994). Não aguento mais. Campinas: Papirus.

Da Silva, A. A. A crise existencial da meia idade e o valor da depressão como um sinal de transformação. Recuperado em 17 set. 2011, em http://www. mitranh.org.br/s2/index.php/gerais/753-a-crise-existencial-da-meia-idade-e-o-valor-da-depressao-como-um-sinal-de-transformacao.html

Dahklke, R. (2009). Depressão: Caminhos de superação da noite escura da alma. São Paulo: Cultrix.

Dalgalarrondo, P. (2008). Psicopatologia e semiologia dos transtornos mentais. Porto Alegre: Artmed.

Dostoievski, F. (2004). Noites brancas e outras histórias. São Paulo: Martin Claret.

Grinberg, L. P. (2003). Jung: 0 homem criativo. São Paulo: FTD.

Hollis, J. (1999). Os pantanais da alma. São Paulo: Paulus.

Johnson, R., \& Ruhl, J. M. (2010). Viver a vida não vivida. Petrópolis: Vozes.

Jung, C. G. (1986). Símbolos da transformação. Petrópolis: Vozes.

Jung, C. G. (1991). Psicologia e Alquimia. Petrópolis: Vozes.

Jung, C. G. (2006). Memórias, sonhos, reflexões. Rio de Janeiro: Nova Fronteira.

Jung, C. G. (2008). 0 homem e seus símbolos. Rio de Janeiro: Nova Fronteira.

Jung, C. G. (2011). A prática da psicoterapia. Petrópolis: Vozes.

Lyra, S. (2001). Nunca mais quero me sentir vulnerável. Curitiba: Lyra.

Mazzocchi, L., Forzani, J., \& Tallarico, A. (1995). Il vangelo secondo Mateo e lo zen. Bologna: Dehoniane.

Sanford, J. A. (1987). Parceiros invisíveis: 0 masculino e o feminino dentro de cada um de nós. São Paulo: Paulus.

Styron, W. (1991). Perto das trevas. Rio de Janeiro: Rocco. 